\title{
INHIBITION OF ADRENALINE-INDUCED FIBRINOLYSIS BY ALPHA-ADRENERGIC BLOCKING AGENTS IN THE RAT
}

\author{
Yasuhiko SASAKI and Shigeyuki TAKEYAMA \\ Pharmacological Research Laboratory, Tanabe Seiyaku (o., Ltd., \\ Toda-shi. Saitama, Japan
}

Accepted June 24, 1974

\begin{abstract}
The fibrinolysis induced by intraperitoneal injection of adrenaline in the rat was inhibited by prior intraperitoneal injection of very low doses of $\alpha$-adrenergic blocking agents. For example, $5 \mu \mathrm{g} / \mathrm{kg}$ of phenoxybenzamine or $10 \mu \mathrm{g} / \mathrm{kg}$ of phentolamine was sufficient to prevent almost completely the fibrinolysis induced by $1 \mathrm{mg} / \mathrm{kg}$ of adrenaline. These $\alpha$-blockers also inhibited the fibrinolysis induced by serotonin and bisobrin, but a much higher dosage was required. Phenoxybenzamine did not inhibit the adrenaline-induced fibrinolysis when the drug was injected after the injection of adrenaline. No inhibitory effect was observed with $\beta$-blockers, dichloroisoproterenol, proncthalol and practolol, even at a dose of $10 \mathrm{mg} / \mathrm{kg}$, although propranolol at a dose of $3 \mathrm{mg} / \mathrm{kg}$ did exert an inhibitory effect. The involvement of peritoneal blood vessels in adrenaline-induced fibrinolysis is suggested.
\end{abstract}

Adrenaline is known to induce fibrinolysis both in humans (1-3) and dogs (4, 5) and has been implicated in accelerated fibrinolysis observed during or immediately after various stress events such as exercise, fear and trauma. However, the exact mechanism of adrenaline-induced fibrinolysis has not been clarified. For example, the adrenergic mechanism of its fibrinolytic action, i.e., by which adrenergic receptor, $\alpha$ or $\beta$, the adrenalineinduced fibrinolysis is mediated, is still unclarified. Using the dog as an experimental animal, Holemans (6) ruled out a specific involvement of either $\alpha$ or $\beta$-adrenergic receptor, since noradrenaline and isoproterenol were both equally effective in enhancing fibrinolysis. In man, prior administration of propranolol did not affect exercise-induced fibrinolysis (7), while the $\beta$-blocker only partially inhibited the fibrinolysis induced by intravenous adrenaline infusion (8). Kral et al. (9) reported a complete inhibition of the adrenaline-induced fibrinolysis in man by a $\beta$-adrenergic blocker, alprenolol. $\alpha$ Adrenergic blockers have not been shown to exert any effect on the adrenaline-induced fibrinolysis in man $(8,10)$.

We undertook to investigate this problem using the rat as an experimental animal and a series of $\alpha$-and $\beta$-adrenergic blocking agents as tools for differentiating the adrenergic receptor of the adrenaline-induced fibrinolysis. This fibrinolytic system of rat stimulated by an i.p. injection of large doses of adrenaline has been used by Schor et al. for screening synthetic fibrinolytic compounds $(11,12)$. In our experiments, the fibrinolytic action

This work was presented in part at the 45 th Annual Meeting of the lapantse Pharmacological Society in April 1972 in Sendai and was published in abstract form in Japan J. Pharmacol. 22, suppl. 1: $120(1972)$ 
of adrenaline in the rat was found to be inhibited by extremely low doses of $\alpha$-adrenergic blockers.

\section{MATERIALS AND METHODS}

Animals

Malc Sprague-Dawley rats $(150-220 \mathrm{~g})$ were fed commercial laboratory chow for more than a week before the start of experiments.

Drugs

DL-phenylephrine $\mathrm{HCl}$, phenoxybenzamine $\mathrm{HCl}$, dibenamine $\mathrm{HCl}$, I-noradrenaline $\mathrm{HCl}$ and serotonin creatinine sulfate were purchased from Tokyo Chemical Industry Co., Ltd., Tokyo: adrenaline $\mathrm{HCl}$, thrombin and DL-noradrenaline $\mathrm{HCl}$ from Sankyo Company, Ltd., Tokyo; phentolamine mesylate (Regitine s $^{2}$ from Takeda Chemical Industries, Ltd., Osaka; urokinase from Midorijuji Co., Ltd., Tokyo. Pronethalol, practolol and propranolol $\mathrm{HCl}$ were generous gifts from I.C.I., England. Bisobrin (EN 1661, 1, 1'tetramethylene-bis-1, 2, 3, 4, -tetrahydro-6, 7-dimethoxyisoquinoline 2HCl, mesoisomer, mp 261-263') was synthesized by Dr. Yasuhiko Sato and Mr. Masao Wada and dichloroisoproterenol (DIC) by Dr. Kiyohiko Mashimo at Organic Chemistry Research Laboratory of Tanabe Seiyaku Co., Ltd. All the doses stated in the text are expressed in terms of the respective chemical forms described above.

Phosphate-citrate buffer: $23.9 \mathrm{~g} \mathrm{Na}_{2} \mathrm{HPO}_{4} \cdot 12 \mathrm{H}_{2} \mathrm{O}$ was dissolved in $900 \mathrm{ml}$ of distilled water, and to this were added solutions of $3.02 \mathrm{~g} \mathrm{KH}_{2} \mathrm{PO}_{4}$ in $250 \mathrm{ml}$ and $0.25 \mathrm{~g}$ trisodium citrate in $100 \mathrm{ml}$. The final $\mathrm{pH}$ of the solution was 7.4. The buffer was heat-sterilized and stored at $4^{\circ} \mathrm{C}$.

Thrombin solution: Thrombin (500 National lnstitutes of Health units) was dissolved in $100 \mathrm{ml}$ sterile physiological saline and stored below $-20^{\circ} \mathrm{C}$ until used. All pipettes and test tubes coming into contact with diluted blood or blood clot were made of polyethylene.

\section{Fibrinolysis assay}

The general method for measurement of fibrinolytic activity was hased on Fearnley's dilute blood clot lysis method $(13,14)$. Drugs were dissolved in saline and injected either i.p. or i.v. via the tail vein. After various intervals of time, blood was withdrawn into a plastic syringe from the abdominal aorta with the animal under ether anesthesia. Onc $\mathrm{ml}$ of the blood was immediately diluted 20 times with ice cold phosphate-citrate buffer. The blood was mixed in an ice bath, and was kept cold until used. Four $\mathrm{nl}$ of the dilute blood was then clotted with thrombin (5 NIH-units) in a test lube. The lube was placed in an ice bath for one hr and then tratnsferred to an incubator maintained at $37^{\circ} \mathrm{C}$. After $3 \mathrm{hr}$ incubation, the remaining clot was separated from the supernatant by discarding the latter and boiled in $10 \mathrm{ml}$ of $0.1 \mathrm{~N} \mathrm{NaOH}$ for 5 min to convert the hemoglobin to alkaline hematin. The concentration of the latter was determined spectrophotomatrically (540) $\mathrm{nm})$. To calculate the percentage of clot lysis, we used the following equation.

$$
\text { Clot lysis }(\%)=100\left[\begin{array}{ll}
\text { O.1. } & (3 \mathrm{hr} \text { incubation) } \\
& 0 . \bar{D} \text {. (0 hr incubation) }
\end{array}\right]
$$




\section{RESULTS}

Fibrinolysis induced by adrenaline, horadrenaline and phenylephrine

Although either i.v. or s.c. injection of adrenaline ( $5 \mathrm{~min}$ after $0.05-30 \mu \mathrm{g} / \mathrm{kg}$, i.v.; 10 min after $1 \mathrm{mg} / \mathrm{kg}$, s.c.) or forced exercise (swimming in water) did not cause any increase in fibrinolysis in the rat, large i.p. doses of the catecholamine brought about dose-dependent increases in the fibrinolytic activity as reported by Schor et al. (Fig. 1). The fibrinolytic activity reached a maximum at about $10 \mathrm{~min}$ after the injection and returned to the normal level in $30 \mathrm{~min}$ (Fig. 2). Noradrenaline and phenylephrine also showed this property, but the maximum fibrinolysis by phenylephrine occurred 5 min after injection (Fig. 2).

Behavior changes caused by the i.p. injection of large doses of adrenaline were weak tachycardia, slight dilation of the pupils, limb weakness and low pelvic position.

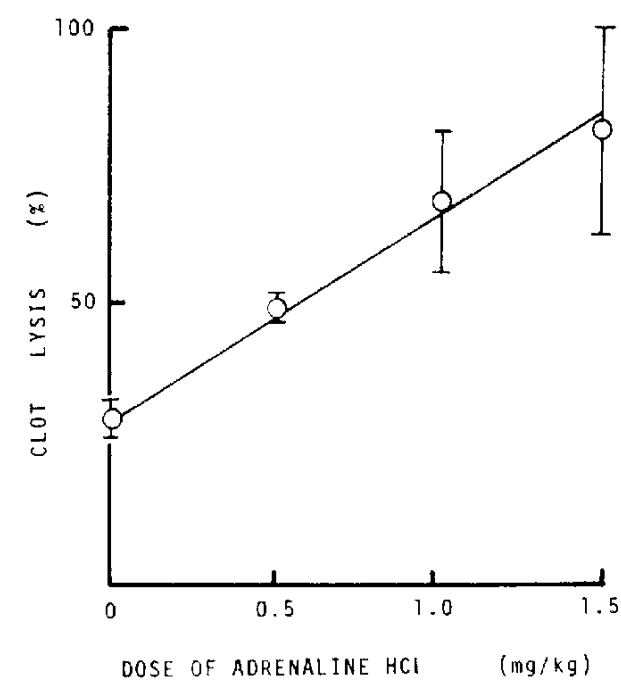

FIG. 1. Dose-response relationship for fibrinolysis induced by adrenaline. The rats were bled 10 min after an i.p. injection of adrenaline $\mathrm{HCl}$. Each point represents mean $\pm S E$ of 4 rats.

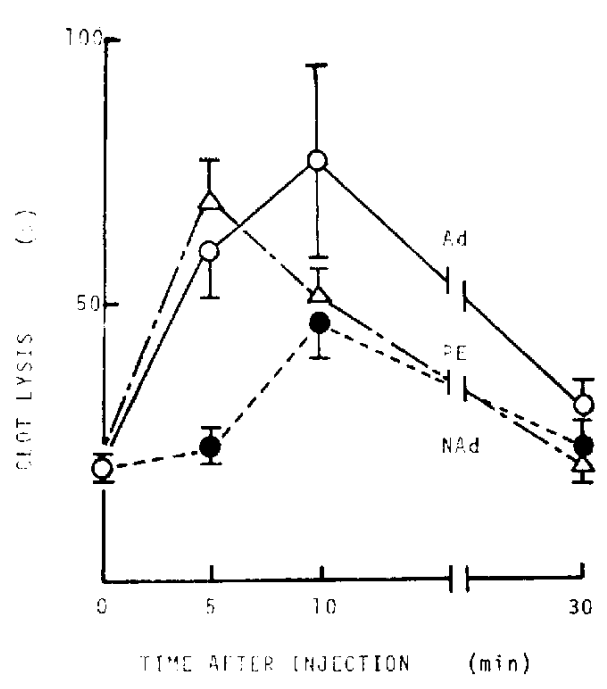

FIG. 2. Fibrinolysis induced by i.p. injections of adrenaline, phenylephrine or noradrenaline into rats. Adrenaline $\mathrm{HCl}$ (Ad, $0.5 \mathrm{mg} / \mathrm{kg}$ ), DL-phenylephrine $\mathrm{HCl}$ (PE, $5 \mathrm{mg} / \mathrm{kg}$ ) and DL-noradrenaline $\mathrm{HCl}$ (NAD, $0.5 \mathrm{mg} / \mathrm{kg}$ ) were injected at 0 min and the rats were bled at the times indicated. Each point represents mean \pm SE of 5 rats.

\section{Effects of $\alpha$-blockers on adrenaline-induced fibrinolysis}

We first examined effects of $\alpha$-blockers (phenoxybenzamine, dibenamine and phentolamine) on the adrenaline-induced fibrinolysis by injecting the blockers i.p. 10 or $20 \mathrm{~min}$ before the injection of adrenaline. As shown in Fig. 3A, the fibrinolysis induced by adrenaline ( $1 \mathrm{mg} / \mathrm{kg}$, i.p.) was found to be completely inhibited by a previous injection of phenoxybenzamine $(5 \mu \mathrm{g} / \mathrm{kg}$ ). From the dose-inhibition curve in Fig. 3A, the dose (ID50) of phenoxybenzarnine that would give a half-maximal inhibition was estimated to be 1.4 


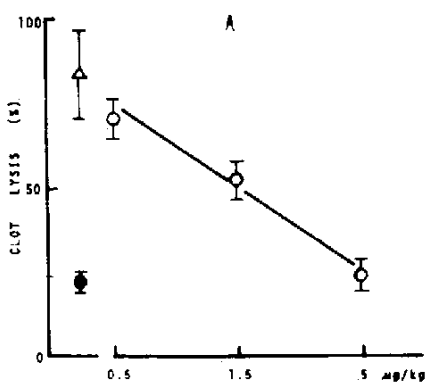

LOG DOSE OF PHEMOXYGEMZANIME HCI

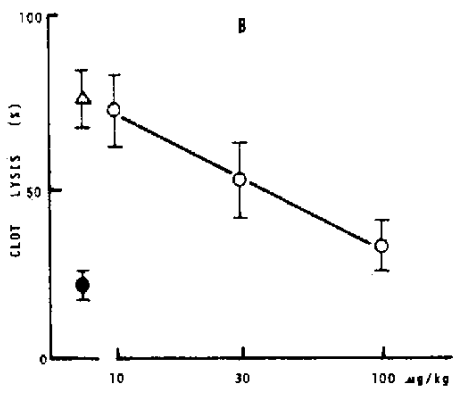

LOG DOSE OF OREEMAMIME HEI

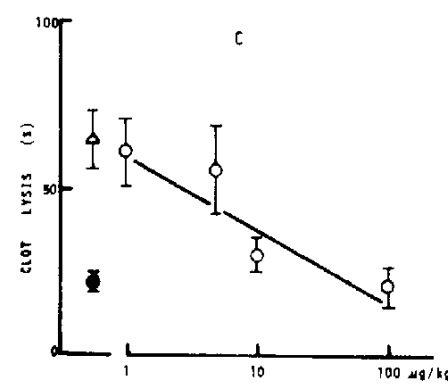

LOS DOSE OF PMERTOLAMIME MESYLATE

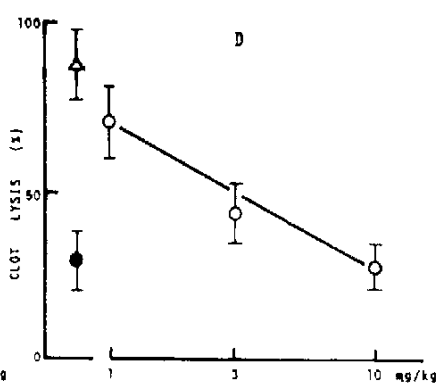

LOG OOSE OF PROPRRMOLIL HCI

FIci. 3. Effects of $\alpha$-adrenergic blockers and propranolol on adrenaline-induced fibrinolysis. Rats were injecte 1 i.p. with phenoxybenzamine $\mathrm{HCl}$ (A) and dibenamine $\mathrm{HCl}$ (B) 20 min before, and with phentolamine mesylate (C) and propranolol $\mathrm{HCl}$ (D) $10 \mathrm{~min}$ before, the i.p. injection of adrenaline $\mathrm{HCl}(1 \mathrm{mg} / \mathrm{kg}$ ) and bled 10 min after the injection of adrenaline. Each point represents mean r. SE of 5 rats. Untreated control rats (O) were given saline twice instead of drug solutions, and adremaline-treated control rats $(A)$ were given saline prior to the adrenaline injection.

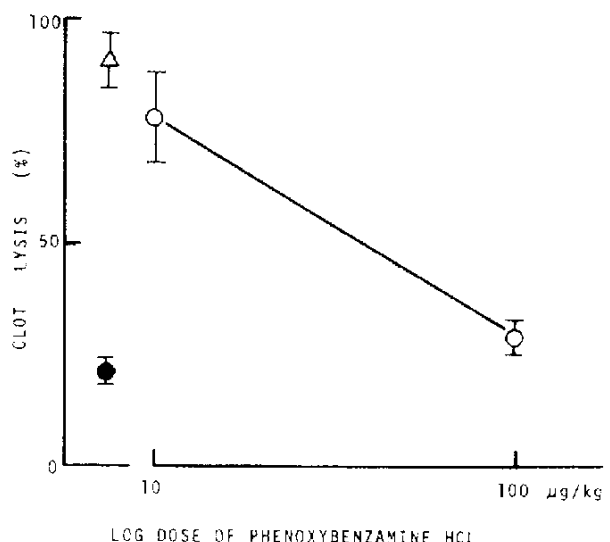

FIc. 4. Effect of i.y. administered phenoxybenzamine on adrenaline-induced fibrinolysis. Rats were injected i.v. with phenoxybenzamine $\mathrm{HCl} 10 \mathrm{~min}$ before the i.p, injection of adrenaline $\mathrm{HCl}(1 \mathrm{mg} / \mathrm{kg})$, and were bled $10 \mathrm{~min}$ after the injection of adrenaline. Each point represents mean $\pm S E$ of 5 rats. Untreated control rats (O) were given saline twice instead of drug solutions, and adrenaline-treated control rats $(\Delta)$ were given saline prior to the adrenaline injection. 
$\mu \mathrm{g} / \mathrm{kg}$. Intravenous injection of phenoxybenzamine was also effective in preventing the adrenaline-induced fibrinolysis, but much higher doses were required to produce significant inhibitions, the ID50 in this case being $30 / \mathrm{gg} / \mathrm{kg}$ (Fig. 4). The inhibitory effects of dibenamine and phentolamine on the adrenaline-induced fibrinolysis were less marked than that of phenoxybenzamine, but inhibitory doses were far less than the dose of adrenaline (Fig. $3 \mathrm{~B}$ and $3 \mathrm{C}$ ). When phenoxybenzamine was injected $5 \mathrm{~min}$ after the injection of adrenaline, no inhibitory effect was observed even at a dose of $100 \mu \mathrm{g} / \mathrm{kg}$. The $\alpha$ blockers added in vitro into the assay system showed no inhibitory effect at a concentration of $50 \mu \mathrm{g} / \mathrm{ml}$. These inhibitors $(100-200 \mu \mathrm{g} / 4 \mathrm{ml}$ diluted blood) were also without effect on the action of urokinase (10 NIH-units/4 $\mathrm{ml}$ diluted blood) in vitro.

One might assume that the $\alpha$-blockers may elicit an intrinsic inhibitor of the fibrinolytic system in the rat. This possibility was tested by examining fibrinolysis of mixed blood samples from $\alpha$-blocker-treated rats and from adrenaline-treated rats. The blood samples withdrawn from rats injected with phenoxybenzamine $(10 \mathrm{mg} / \mathrm{kg}, i . \mathrm{p}$.) or phentolamine (15 $\mathrm{mg} / \mathrm{kg}$, i.p.) $20 \mathrm{~min}$ after the injection did not inhibit the fibrinolysis of blood samples taken from rats injected with adrenaline $(1 \mathrm{mg} / \mathrm{kg}$, i.p., blood withdrawn $10 \mathrm{~min}$ after the injection) when both were mixed in vitro. From these experiments, it was concluded that the inhibition of adrenaline-induced fibrinolysis by the $\alpha$-blockers is caused neither by direct inhibition of the fibrinolytic system nor by production of endogenous inhibitors of fibrinolysis in the $\alpha$-blocker-treated animal.

\section{Effects of $\beta$-blockers on adrenaline-induced fibrinolysis}

Effects of the $\beta$-blockers propranolol, DCl, pronethalol and practolol on the adrenaline-induced hibrinolysis are shown in Fig. 3D and Fig. 5. The pre-treatment of rats with $\mathbf{D C l}$, pronethalol or practolol dic not inhibit the adrenaline-induced fibrinolysis even at a dose of $10 \mathrm{mg} / \mathrm{kg}$, but rather stimulated it slightly (Fig. 5). Propranolol, on the other

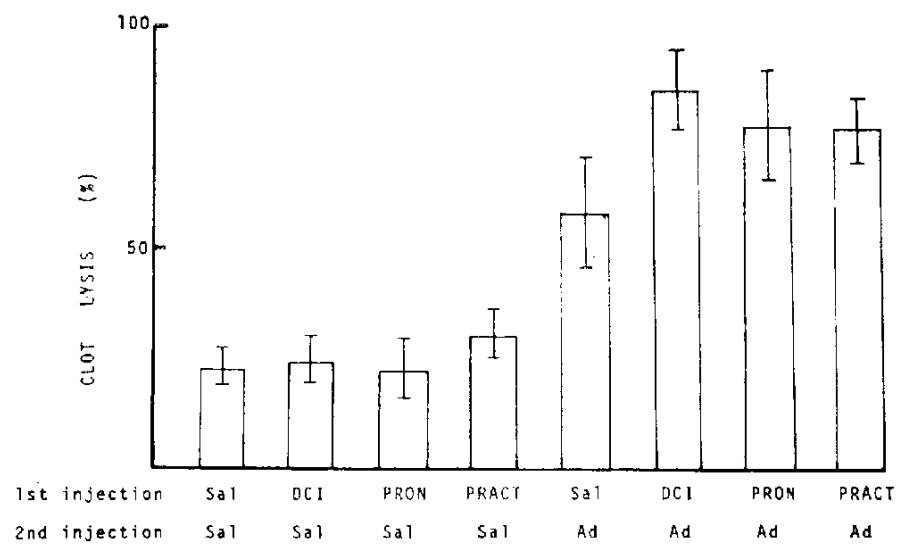

FIG. 5. Effect of $\beta$-adrenergic blockers on adrenaline-induced fibrinolysis. Rats were injected i.p. with $10 \mathrm{mg} / \mathrm{kg}$ of dichloroisoproterenol (DCI), pronethalol (PRON) and practolol (PRACT) $10 \mathrm{~min}$ before the i.p. injection of adrenaline $\mathrm{HCl}$ (1 $\mathrm{mg} / \mathrm{kg}$ ), and bled $10 \mathrm{~min}$ after the injection of adrenaline. Each bar represents mean $\pm \mathrm{SE}$ of 5 rats. 
hand, exerted an inhibitory effect at a dose of $3 \mathrm{mg} / \mathrm{kg}$, and the ID50 for propranolol was $1.9 \mathrm{mg} / \mathrm{kg}$ as shown in Fig. 3D. This value was much higher than those tor the $\alpha$-blockers.

Effects of phenoxybenzamine on phenylephrine-, noradrenaline-, serotonin- and bisobrininduced fibrinolyses

Effects of phenoxybenzamine on the actions of other fibrinolysis inducers were investigated. The fibrinolysis induced by phenylephrine $(5 \mathrm{mg} / \mathrm{kg}$, i.p.) and noradrenaline ( $1 \mathrm{mg} / \mathrm{kg}$, i.p.) was found to be completely inhibited by a previous injection of phenoxybenzamine $(30 \mathrm{rg} / \mathrm{kg}, \mathrm{i} . \mathrm{p}$.). Fig. $6 \mathrm{~A}$ illustrates the dose-inhibition relationship of the pretreatmen with phenoxybenzamine for the fibfrinolysis induced by noradrenaline, and shows that the noradrenaline-induced fibrinolysis (ID50:=1.4 $\mathrm{gg} / \mathrm{kg}$ ) is as sensitive to the inhibitory action of phenoxybenzamine as the adrenaline-induced fibrinolysis (ID50. $1.4 \mu \mathrm{g} / \mathrm{kg})$. Serotonin is also known to induce fibrinolysis in rats (12), rabbits (15) and man (16). As shown in Fig. 6B, phenoxybenzamine also inhibited the serotonin-induced fibrinolysis, but a much higher dosatge (ID50 $=2.5 \mathrm{mg} / \mathrm{kg}$ ) was required. Schor et al. have
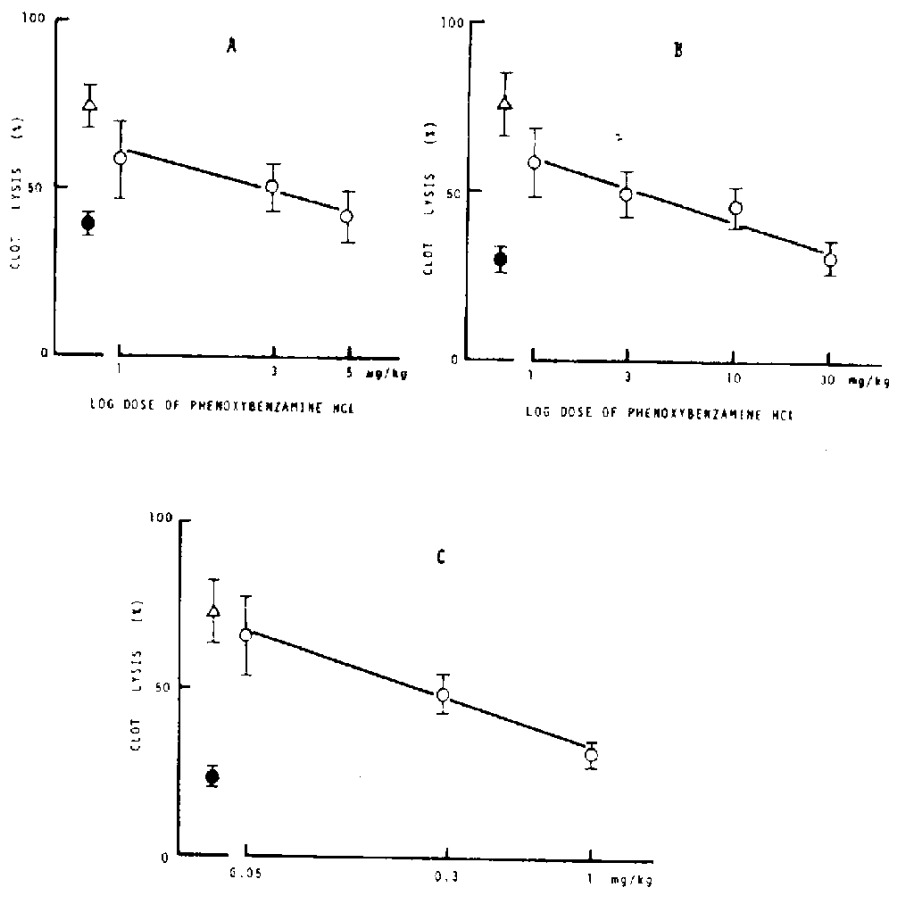

Fig. 6. Effect of phenoxybenzamine on noradrenaline-, serotonin- and bisobrin-induced fibrinolyses. Rats were injected i.p. with phenoxybenzamine $\mathrm{HCl} 20 \mathrm{~min}$ before injection of the fibrinolytic agents L-noradrenaline $\mathrm{HCL}$ (A, $1 \mathrm{mg} \mathrm{kg}$, i.p.), seroconin creatinine sulfate $B, 10 \mathrm{mg} / \mathrm{kg}, \mathrm{i} . \mathrm{p}$.) and bisobrin $(\mathrm{C}, 10 \mathrm{mg} / \mathrm{kg}, \mathrm{i} . v$.$) , and$ were bled 10 min after the injection of $\mathrm{L}-$ noradrenaline and serotonin or $5 \mathrm{~min}$ after the injection of bisubrin. Each point represents mean $\pm \mathrm{SE}$ of 5 (A and $\mathrm{B}$ ) or 4 (C) rats. Untreated control rats (O) were given saline twice instead of drug solutions, and fibrinolytic agent-treated control rats (A) were given saline before the injection of the fibrinolytic agents. 
reported that the synthetic compound bisobrin, when properly administered, possesses a fibrinolytic activity without serious pharmacological side effects $(11,12,17)$. We therefore studied the effect of phenoxybenzamine on the bisobrin-induced fibrinolysis in rats (Fig. 6C). The bisobrin-induced fibrinolysis was also inhibited by phenoxybenzamine ( $1 \mathrm{mg} / \mathrm{kg}, \mathrm{i} . \mathrm{v}$ ) and its sensitivity (ID50 $=320 \mu \mathrm{g} / \mathrm{kg}$ ) to phenoxybenzamine was between that of the adrenaline- and serotonin-induced fibrinolyses.

Constriction of mesenteric arteries by adrenergic amines and its inhibition by phenoxybenzamine

The fact that the i.p. route is more effective than the i.v. route for both adrenaline and phenoxybenzamine suggests that the site of action may be blood vessels in the peritoneal cavity. Therefore, the rat peritoneum was exposed and effects of the above compounds on the mesenteric arteries and veins were observed under a low-magnification microscope. When one drop of an adrenaline solution $(200 \mu \mathrm{g} / \mathrm{ml}$ saline) was allowed to fall onto the peritoneum, the mesenteric arteries which came into contact with the solution constricted instantaneously, while the veins apparently remained unaffected. If the adrenaline solution was dropped over an area where the tissues had previously been moistened with one drop of phenoxybenzamine solution $(20 / \mathrm{gg} / \mathrm{ml}$ saline), the constriction of the arteries was no longer observed. Similar phenomena were observed when the adrenaline solution was replaced by solutions of noradrenaline and phenylephrine.

\section{DISCUSSION}

The rat is not considered a suitable experimental animal to use as a substitute for humans in studies of fibrinolysis, since the level of antifibrinolytic activity in rat plasma is much higher than that in human plasma (18). Adrenaline-induced fibrinolysis as measured by the dilute whole blood lysis test was observed only when rats were treated with high i.p. doses of adrenaline (12). These high, but sublethal, doses would probably be enough to elicit the plasminogen activator or other afibrinolytic activators in amounts sufficent to overcome the high level of antifibrinolytic activity. Although it is not known to what extent this fibrinolysis induced by adrenaline in the rat shares common aspects with physiological fibrinolysis in man, its inhibition by extremely low doses of $\alpha$-adrenergic blockers deserves attention. To our knowledge, in no case has an inhibition of adrenaline action by $\alpha$-adrenergic blockers been observed at such low $\alpha$-blocker/adrenaline dose ratios as used in the present study. Furthermore, this inhibition scems to have resutled from a specific blockade of the adrenergic receptor, because the phenylephrine- or noradrenalineinduced fibrinolysis was also prevented by low doses of phenoxybenzamine, while a much higher dosage was required to inhibit the fibrinolyses induced by other types of fibrinolytic agents, serotonin and bisobrin. Inhibition of plasmin or urokinase activity by the $\alpha$ adrenergic blockers or a release of antiplasmin from the animal tissue after phenoxybenzamine injection has been ruled out. The lack of an inhibitory effect by $\alpha$-blockers in adrenaline-induced stimulation of fibrinolysis in man $(8,10)$ indicates that the elevation of fibrinolytic activity by a constant infusion of adrenaline involves different mechanisms. 
Among the four $\beta$-adrenergic blockers tested, only propranolol showed an inhibition at relatively high doses, while the other three were rather stimulatory. This slight activation of fibrinolysis by the $\beta$-blockers suggests that the $\beta$-adrenergic action of adrenaline may have been suppressed so as to let the antagonistic $\alpha$-adrenergic property exert its full action on the target tissue (e.g. blood vessels). In man, propranolol partially (8) and alprenolol completely (9) inhibited the increase in fibrinolytic activity brought about by adrenaline infusion.

Holemans (6) has suggested various mechanisms by which plasminogen activator could be released from vessel walls into the circulation by the action of vasoactive substances on the vessel walls. The most likely site of action of i.p. administered adrenaline would then be the mesenteric blood vessels which would receive direct, sustaining actions of the injected adrenaline, since the i.p. route was the only effective route of injection for the fibrinolytic action of adrenaline. The fact that a much smaller dosage is required for a similar degree of inhibition by phenoxybenzamine when it is administered i.p. rather than i.v. also indicates that the site of the fibrinolytic action of adrenaline is in the pertioneal cavity. The inhibition by phenoxybenzamine of the adrenaline-induced constriction of mesenteric arteries correlates with the inhibition of the adrenaline-induced fibrinolysis by the $\alpha$-adrenergic blocker. Sato and Nagao in this laboratory showed that an i.p. injection of adrenaline $(1 \mathrm{mg} / \mathrm{kg})$ did not produce the typical rise in the systemic blood pressure in the rat at least for $30 \mathrm{~min}$, whereas a prior injection of phenoxybenzamine $(10 \mathrm{~kg} / \mathrm{kg}$, i.p.) by the same route induced the pressor response just as observed when adrenaline was given intravenously (unpublished observation). The intraperitoneal adrenaline may not enter the circulation due to the constriction of the peritoneal blood vessels which in turn would induce local hemostasis, while with phenoxybenzamine, an antagonist of the vasoconstriction by adrenaline, adrenaline would enter the circulation freely through the walls of the peritoneal blood vessels and exert its systemic pressor action. The plasmin activator is probably released from the constricted areas of the peritoneal blood vessels into the circulation, and phenoxybenzamine may have a strong affinity towards the receptor of the peritoneal blood vessels upon which adrenaline exerts its vasoconstrictor action.

Acknowledgements: The authors wish to express their gratitude to Dr. K. Abe for his constant encouragement, to Dr. T. Nagao and Mr. M. Sato for helpful advice and to Mr. H. Okonogi for excellent technical assistance.

\section{REFERENCES}

1) Biggs, R., Macfarlane, R.G., and Pilling, J.: Lancet i, 402 (1974)

2) Genton, E., Kren, F. and Von Kaulla, K.N.: Am. J. Med. 31, 564 (1961)

3) Sherry, S., Lindemeyer, R.I., Fletcher, A.P. and Alkjaersig, N.: J. clin. Invest. 38, 810 (1959)

$4)$ Cho, M.H. and Choy, W.: Fedn. Proc. 23, 354 (1964)

5) Von Kaulla, K.N.: Arzneim.-Forsch. 15, 246 (1965)

6) Holemans, R.: Am. J. Physiol. 208, 511 (1965)

7) Cohfn, R.J., Epstein, S.E., Cohen, L.S. and Dennis, L.H.: Lancet ii, 1264 (1968)

8) Cash, J.D., Woodfield, D.G. ANd Allan, A.G.E.: Br. J. Haemat. 18, 487 (1970) 
9) Kral, J.G., Ablad, B., Johnsson, G. and Korsan-Bevgisen, K.: Europ. I. clin. Pharmacol. 3, $144(1971)$

10) Tanser, A.R. and Hugh Smellie: Ciin. Sci. 26, 375 (1964)

11) Flifedner, Jr., L.J., Schor, J.M., Myers, M.J. and PaChter, I.J.: J. med. Chem. 14, 580 (1971)

12) Schor, J.M., Steinberger, V., Tutko, E., Aboulafia, S., Pachter, i.J. aidd Jacobsen, R.: Chemical Control of Fibrinolysis-Thrombolysis, Edited by J.M. ScHOR, p. 113, Wilcy, Now York (1970)

13) Fearnley, G.R.: Fibrinolysis, p. 30, Edward Arnold Publishers Ltd., London (1965)

14) Billimoria, J.D., Drysdale, J., James, D.C. and Maclagen, N.F.: Lancet ii, 471 (1959)

15) Kwaan, H.C., Lo, R. And MCFadzean, A.J.S.: Br. J. Haemat. 4, 51 (1958)

16) KwaAn, H.C., Lo, R. Avd MCFADzeaN, A.I.S.: Clin. Sci. 16, 255 (1957)

17) Ambrus, J.L., Ambrus, C.M., Jacobsen, R., Schor, J.M. And Jainchill, J.L.: Curr. Ther. Res. 12, 451 (1970)

18) Heduin, A.M., Monkhouse, F.C. and Milojevic, S.M.: Can. J. Physiol. Pharmacol. 50, II (1972) 